\title{
Radiation to Greater than 25 Percent of Bone Marrow
}

National Cancer Institute

\section{Source}

National Cancer Institute. Radiation to Greater than 25 Percent of Bone Marrow. NCI Thesaurus. Code C156802.

Bone marrow irradiation targeting greater than 25 percent of the total bone marrow. 